\title{
EMIGRAÇÃO, REGRESSO E DESENVOLVIMENTO NO BARROSO (PORTUGAL)
}

\author{
Maria Ortelinda BARROS GONÇALVES \\ Universidade Portucalense, CEPESE
}

Recibido: 28/03/2011

Aceptado: 27/06/2011

RESUMO: Embora a ruralidade englobe traços comuns, o meio rural caracteriza-se por uma imensa diversidade. Estabelecer tipologias capazes de captar esta diversidade é um dos mais importantes objectivos das pesquisas contemporâneas, direccionadas à dimensão espacial do desenvolvimento. O presente trabalho, procurando ser um contributo nesta matéria, é a súmula de alguns aspectos da investigação sobre o regresso dos emigrantes a um concelho do interior - norte de Portugal. O mesmo baseia-se na análise dos dados recolhidos em inquérito por questionário, efectuado a $51 \%$ dos emigrantes regressados a este território, partindo das seguintes questões: Quais as implicações do regresso dos emigrantes no desenvolvimento do espaço em estudo? Que políticas/estratégias de gestão territorial devem ser implementadas para a fixação/atracção da população?.

PALAVRAS CHAVE: Emigração, Regresso, Desenvolvimento.

\section{EMIGRATION, RETURN AND DEVELOPMENT IN BARROSO (PORTUGAL)}

ABSTRACT: Although the countryside encompasses common features, the rural area is characterised by a vast diversity. To establish typologies capable of capture this diversity is one of the most important objectives of current searches, focused on the spatial dimension of development. The present work, aims to be a contribution to this subject, providing a summary of some aspects of the investigation concerning the emigrant return to a county in the North and interior of Portugal. This work is based on the analysis of the data collected through inquiry by questionnaire, undertaken to $51 \%$ of the emigrants returned to this territory, starting from the following questions: What are the implications of the emigrant return in the development of the geographical space of study? What politics/strategies of territorial management must be implemented for the settling/attraction of population?.

KEY WORDS: Emigration, Return, Development.

\section{INTRODUÇÃO}

$\mathrm{Na}$ actualidade, torna-se difícil às populações das áreas rurais periféricas escaparem aos efeitos da globalização, agravando-se as dificuldades de o seu desenvolvimento ocorrer de forma harmoniosa e sustentada. Os territórios 
rurais sofrem de privações em múltiplos domínios: emprego, saúde, educação, vida social, etc. Neste contexto, e como parte integrante das estratégias de sobrevivência, ocorrem as migrações internacionais. Segundo BRAGA (1993), a fragilidade e potencialidades de cada espaço rural impõem soluções consistentes, viáveis e inovadoras, que garantam a sua recuperação e revitalização económica e social, fazendo-as evoluir para novos patamares de qualidade e sustentabilidade. A causa mais evidente das migrações é a disparidade inter-regional quanto aos níveis de rendimento, de emprego e de bem-estar social (CASTLES, 2005:22). Com o incremento da mobilidade proporcionada pelo desenvolvimento dos meios de transporte e das novas tecnologias de informação e comunicação, as migrações internacionais são um dos principais factores de transformação e de desenvolvimento dos países e/ou regiões. Um conhecimento mais vasto sobre os fluxos migratórios internacionais, a nível das consequências e impactos nos países emissores e receptores, contribuirá certamente para a compreensão da nova ordem do séc. XXI. Os migrantes não são mais "enraizados"; em vez disso, movem-se num espaço inter-fronteiras internacionais e entre culturas e sistemas sociais (GLICK E SCHILLER 1997; LEVIT 1998), adoptando estratégias de vida (bi e ou multi-nacionais e bi e ou multi-culturais, como reconhecimento de múltiplas afiliações e identidades. Estes migrantes incorporam não só as remessas económicas mas também as remessas sociais para as suas terras de origem impulsionando estas à mudança. Assim, a migração internacional é pautada pela criação de pontes de encontro, de redes entre sociedades distintas, com base nas novas tecnologias de comunicação e informação. Esta realidade territorial propicia o aparecimento de comunidades transnacionais que conseguem gerir a pertença a espaços sociais diferentes, criando elos intereconómicos, interculturais e outros. Neste sentido, os migrantes no mundo transnacional e global estão envolvidos na construção da nação de mais do que um Estado. As entidades nacionais não são só ofuscadas mas também negociadas ou construídas (PORTES, 1999).

O presente trabalho é a súmula de alguns aspectos da investigação sobre o regresso de emigrantes a um concelho do interior - norte de Portugal, tendo como suporte um estudo mais vasto feito neste território (GONÇALVES, 2009). Baseia-se na análise dos dados recolhidos em inquérito por questionário efectuado no ano de 2006 a 51\% dos emigrantes regressados ao seu local de origem, partindo das seguintes questões:

1) Quais as implicações do regresso dos emigrantes no desenvolvimento do espaço em estudo?

2) Que políticas/estratégias de gestão territorial devem ser implementadas para a fixação/atracção da população? 
A investigação mais alargada e que serviu de base ao estudo apresentado (GONÇALVES, 2009), para além de colocar a questão do desenvolvimento rural numa perspectiva integrada e endógena, integra, a migração presente/recente local, a questão da cidadania dual, analisa o emigrante actual numa perspectiva transnacional, com múltiplas relações (familiares, económicas, sociais e políticas) que ampliam as fronteiras, colocando em intercontacto o local e o global. Em termos metodológicos, foi feita, a articulação entre múltiplas técnicas de recolha e tratamento de informação de cariz quantitativo e qualitativo. Esta triangulação técnico-metodológica sempre que possível, foi combinada com a perspectiva de triangulação teórica.

\section{QUADRO GEOGRÁFICO E EMIGRAÇÃO}

O Concelho de Boticas é o palco da nossa investigação. Ocupando uma área de $322 \mathrm{~km}^{2}$, o concelho de Boticas estende-se do rio Tâmega à serra de Alturas e das serras de Melcas e dos Marcos às serras do Leiranco e Pastoria, integrando-se geograficamente na zona de transição do maciço "galaicoduriense" para o sistema planáltico da Meseta Norte.

O concelho de Boticas integra-se num todo que é a NUTE III - Alto Trásos-Montes, separado do concelho de Chaves em grande parte pelo Rio Tâmega, comunga com os concelhos da margem esquerda do mesmo, na região denominada por "Alto Tâmega".Com Montalegre, constitui a região do Barroso.

«O Barroso é uma região demarcada desde os primórdios da $1^{\mathrm{a}}$ dinastia, tendo sido dada por D. João I ao seu amigo e companheiro de armas, D. Nuno Alvares Pereira, que, nestas paragens, casou com uma viúva jovem e sem mácula, D. Leonor Alvim» (MARTINS, 1992:18). Administrativamente, o concelho é actualmente constituído por dezasseis freguesias e cinquenta e duas aldeias.

Longe do mar e isolado das suas influências pelas barreiras montanhosas do Gerês, Cabreira, Padrela, Alvão e Marão, o Alto Trás-os-Montes, em que se inclui o presente concelho, tem um clima contrastante. Segundo VERGÍlIO TABORDA (1932), o facto de ser uma "zona planáltica" e montanhosa, modelada por vales mais ou menos profundos, contribui para a multiplicação dos contrastes climatéricos. Domina, contudo, um clima exposto às influências continentais, mas em que a variedade de condições topográficas e de exposição gera oposições muito acentuadas.

Na generalidade, nestas regiões, os Invernos são longos e rigorosos, durante os quais é frequente ocorrerem fortes nevões e condições para geadas. Estas, com probabilidades de ocorrência em todos os meses do ano excepto nos 
meses de Julho e Agosto, causam, muitas vezes, elevados prejuízos à agricultura local, nomeadamente no período Primaveril - Estival.

Climaticamente ${ }^{1}$, podemos dividir a região do Barroso em Terra Fria de Montanha, Terra Fria de Planalto e Terra de Transição. A Terra Fria de Montanha corresponde à Serra do Barroso, desenvolve-se entre os 900/1000 metros e 1200/1300 metros de altitude, com temperaturas médias entre os $8^{\circ}-10^{\circ} \mathrm{C}$ e precipitação acima dos $1200 \mathrm{~mm}$. Caracteriza-se pela queda de neve durante o Inverno. A Terra Fria de Planalto ocorre a menor cota, ou seja, entre os 600/700 a 900/1000 metros, com temperaturas médias entre os $10^{\circ}-12,5^{\circ} \mathrm{C}$ e precipitações acima dos $1200 \mathrm{~mm}$. Os Invernos são frios e prolongados e os Verões curtos e quentes; o período de geada é mais frequente entre os meses de Outubro e Maio. A Terra de Transição é morfologicamente uma nova realidade; a sua altitude atinge apenas 400/500 metros, com precipitações entre os 800 e $1000 \mathrm{~mm}$ e temperaturas médias compreendidas entre os $12^{\circ}$ e $14^{\circ} \mathrm{C}$.

A fisiografia do regime pluviométrico define-se, em grandes linhas, por precipitações abundantes no Outono e Inverno. Em média, o mês mais chuvoso é o de Janeiro, seguindo-se, por ordem decrescente, os de Novembro, Março, Dezembro e Fevereiro, que registam cerca de $65 \%$ da precipitação total anual. A precipitação média anual varia entre os 600 e $1200 \mathrm{~mm}$, de acordo com as diferentes altitudes.

A diversidade morfológica é uma realidade para uma vasta e variada superfície de modelado montanhoso, como é o caso da Serra das Alturas, situada no Centro do Barroso, com 1279 metros de altitude e orientada de NE a SW; sucedem-se formas planálticas cujas cotas atingem os $700 \mathrm{~m}$ de altitude. O predomínio das formações graníticas do pré-câmbrico-arcaico é traço característico da região transmontana. As formações silúricas têm ainda importância, especialmente os xistos da parte superior do sistema (TABORDA, 1932:33).

A região em estudo é drenada pelo rio Tâmega e seus afluentes (Beça, Terva, e Ribeira de Covas). A rede hidrográfica modela em granito da Serra o seu percurso, fecundando várzeas e campos, "refrescando" a vila e as aldeias. As serras rodeiam vales cheios de "córregos" e outras linhas de água, em cujas margens ou encostas se alcandora um reduzido povoamento concentrado.

\footnotetext{
${ }^{1}$ Agroconsultores E COBA, (1991): Carta de solos, carta da utilização actual e carta de aptidão da terra, UTAD, Vila-Real.
} 
A engenharia hidráulica é complexa, mas completamente adaptada às exigências do Homem; assim, são inúmeros os poços que abastecem os pequenos regados das "várzeas", das povoações e dos lameiros, assegurando, durante o Inverno, a rega de lima ${ }^{2}$.

Os baldios situam-se principalmente nas encostas e territórios mais altos, de terreno sáfaro, impróprios para a cultura e sujeitos ao regime de propriedade colectiva. Nos vales e nas encostas, existem lameiros sempre verdejantes, com água abundante, e as terras de cultivo.

Trata-se de um território com população muito envelhecida e carece de desenvolvimento. Em 4 décadas, especificamente no período 1960-2001, o grupo de idade jovem (0-14 anos) perdeu praticamente o mesmo que ganhou o grupo de idade idosa (>64 anos), (FIGURAS 1 e 2).

Em razão do visível carácter cumulativo de reces1são demográfica, é atribuída ao concelho de Boticas a denominação de "espaço rural profundo". O duplo envelhecimento, uma taxa de analfabetismo em 2001 ainda de 24\%, e um constante aumento da taxa de desemprego da população residente, afectando essencialmente o género feminino, afirmam-se como uma tendência dominante da realidade concelhia.

Figura 1. Pirâmide etária de 1960

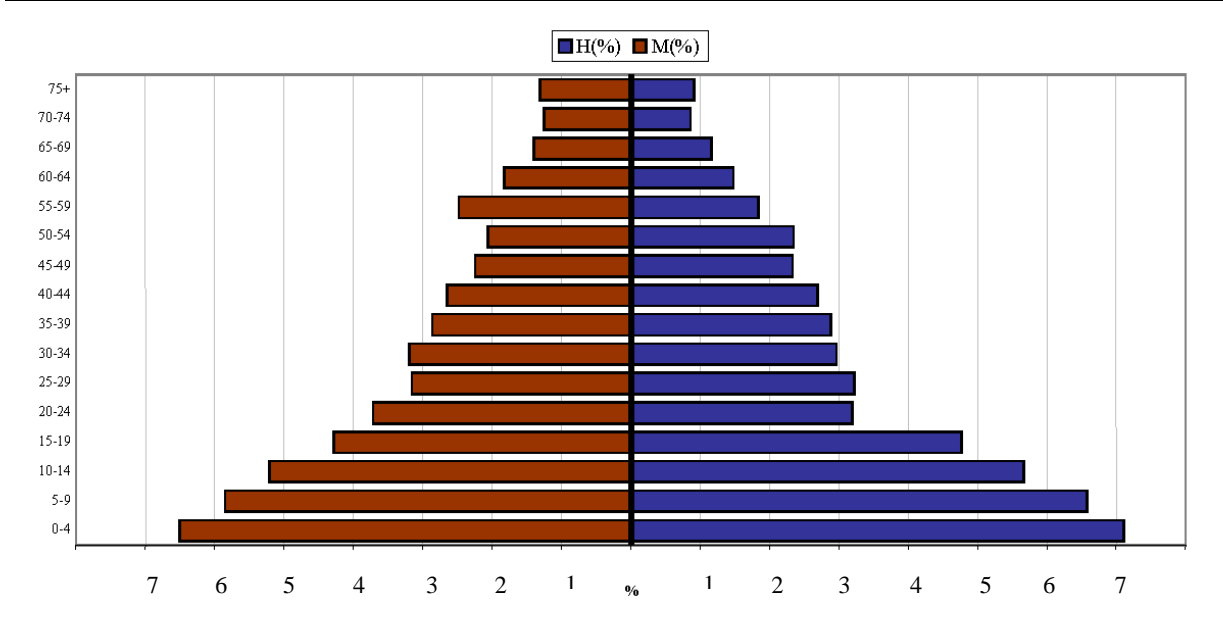

FONTE: INE, Recenseamento Geral da população, 1960.

\footnotetext{
${ }^{2}$ Rega dos prados permanentes sem intuito de abastecimento de água à planta, mas sim para a proteger das baixas temperaturas através da libertação do calor latente de congelação.
} 
Figura 2. Pirâmide etária de 2001

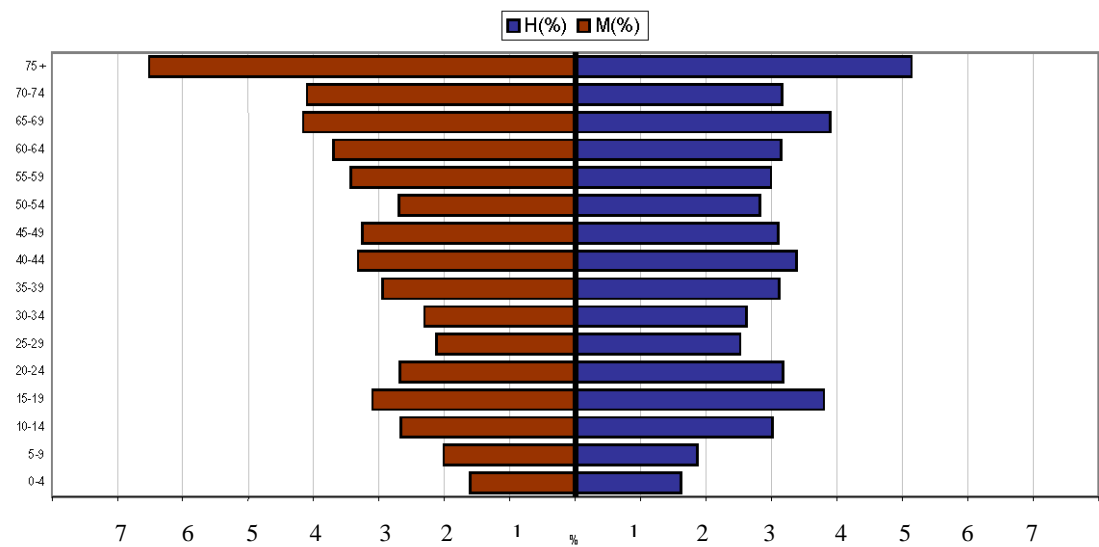

FONTE: INE, Recenseamento Geral da população, 2001.

Quadro 1: População e Atractividade do Concelho de Boticas

\begin{tabular}{lrrrrrrr}
\hline \multicolumn{1}{c}{ Concelhos } & 1991 & 2001 & $a$ & $b$ & \multicolumn{3}{c}{ Rácios } \\
Alturas do Barroso & 637 & 444 & $-30,30$ & 2 & -195 & $-30,6$ & $-43,9$ \\
Ardãos & 457 & 311 & $-31,95$ & -4 & -142 & $-31,1$ & $-45,7$ \\
Beça & 1.064 & 1.031 & $-3,10$ & -11 & -22 & $-2,1$ & $-2,1$ \\
Bobadela & 487 & 354 & $-27,31$ & 12 & -145 & $-29,8$ & $-41,0$ \\
Boticas & 1.066 & 1.065 & $-0,09$ & -14 & 13 & 1,2 & 1,2 \\
Cerdedo & 276 & 176 & $-36,23$ & -2 & -98 & $-35,5$ & $-55,7$ \\
Codessoso & 194 & 168 & $-13,40$ & -1 & -25 & $-12,9$ & $-14,9$ \\
Covas do Barroso & 477 & 348 & $-27,04$ & -4 & -125 & $-26,2$ & $-35,9$ \\
Curros & 113 & 87 & $-23,01$ & 1 & -27 & $-23,9$ & $-31,0$ \\
Dornelas & 584 & 413 & $-29,28$ & -1 & -170 & $-29,1$ & $-41,2$ \\
Fiães do Tâmega & 201 & 167 & $-16,92$ & -2 & -32 & $-15,9$ & $-19,2$ \\
Granja & 341 & 266 & $-21,99$ & -2 & -73 & $-21,4$ & $-27,4$ \\
Pinho & 600 & 478 & $-20,33$ & 1 & -123 & $-20,5$ & $-25,7$ \\
S. Salvador Viveiro & 481 & 345 & $-28,27$ & -1 & -135 & $-28,1$ & $-39,1$ \\
Sapiãos & 659 & 526 & $-20,18$ & -1 & -132 & $-20,0$ & $-25,1$ \\
Vilar & 299 & 238 & $-20,40$ & -1 & -60 & $-20,1$ & $-25,2$ \\
\hline Total do Concelho & 7.936 & 6.417 & $-19,14$ & -28 & -1491 & $-18,8$ & $-23,2$ \\
\hline Total do País & 9.867 .147 & 10.356 .117 & 4,96 & 88.770 & 400.200 & 4,1 & 3,9 \\
\hline
\end{tabular}

a, Variação \% (2001/1991), b, Evolução do Saldo Fisiológico entre 1991 e 2001; c, Atracção / Repulsão.

FONTE: INE, Recenseamento Geral da População 1991 e 2001 (Elaboração própria)

No último decénio em estudo (1991-2001), o concelho sofreu uma perda populacional de 19,1\% (-1519 habitantes). Grande parte desta perda resultou 
da tendência de o índice de atractividade das diversas freguesias ser cada vez mais negativo. O QUADRO 1 confirma a dinâmica emigratória como principal factor responsável pelas divergências demográficas registadas.

Esta realidade, pode concluir-se, não só pela observação das pirâmides etárias dos anos de 1960 e 2001 mas também pelo aumento do índice de envelhecimento registado no concelho (FIGUA 3).

Figura 3. Indice de Envelhecimento

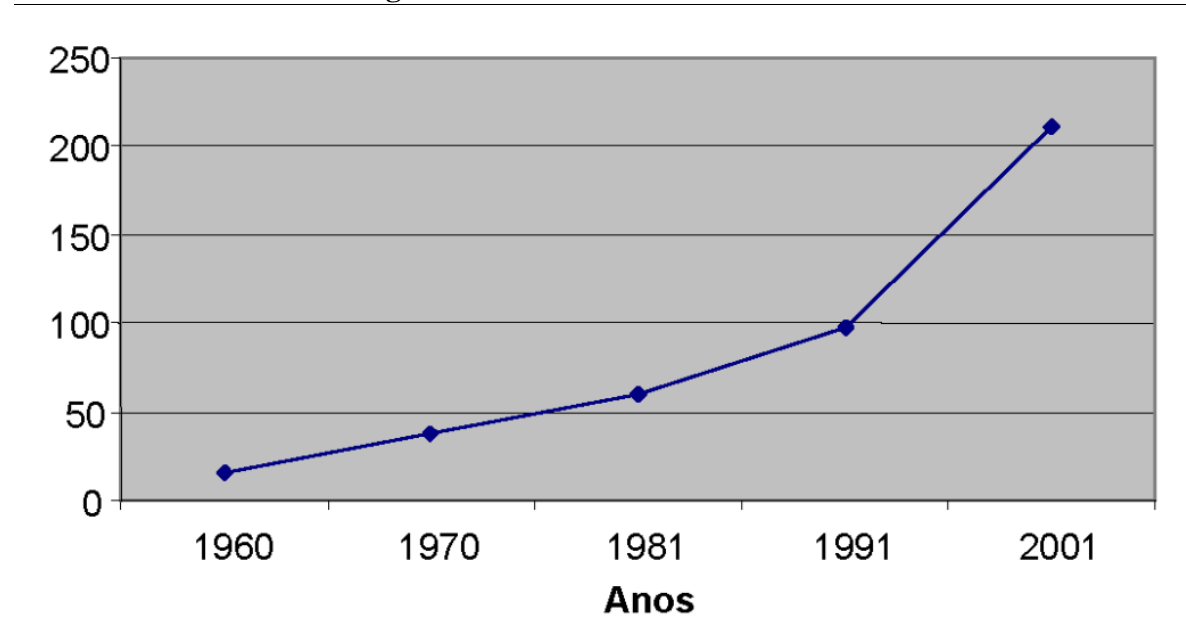

Em 1960, o valor do índice de envelhecimento (IE) foi de 15,2, o que denota franca superioridade estatística do grupo de idades-jovens; no entanto, no decorrer dos anos, o panorama modificou-se, atingindo a população em estudo um índice de envelhecimento ${ }^{3}$ de 210,8 . Boticas é um dos concelhos mais envelhecidos do Alto Trás-os-Montes (GONÇALVES, 2003).

O duplo envelhecimento demográfico tem constituído uma evolução partilhada por todas as populações do continente português, essencialmente as do interior (BARRETO, 2000, p.461). O concelho em estudo regista a maior perda populacional, em termos percentuais, de toda a Região Norte (GONÇALVES, 2009).

A evolução da relação entre o número de activos e a população residente deverá, em princípio, reflectir o desenvolvimento económico e social de uma área. O seu valor será tanto mais elevado quanto maior for o número de acti-

\footnotetext{
3 Índice de envelhecimento é a relação entre a população idosa (com 65 e mais anos) e a população jovem (dos zero aos 14 anos) por cada 100 indivíduos.
} 
vos e diminuirá à medida que a escolaridade obrigatória aumenta e a idade da reforma decresce.

A evolução da taxa de actividade espelha também a mobilidade da população de um determinado espaço. No concelho em estudo, o contínuo surto emigratório é a principal explicação para a diminuição da sua população activa e para o envelhecimento acentuado da população residente e consequente progressivo despovoamento local. Esta diminuição assume particular importância no sexo feminino que, embora tradicionalmente detentor de taxas de actividade inferiores às do sexo masculino, atinge, na última década, aproximadamente menos oito pontos percentuais (QUADRO 2).

Quadro 2: Taxa de Actividade por sexo

\begin{tabular}{rrrr}
\hline Anos & Homens e Mulheres & Homens & Mulheres \\
\hline 1991 & $39,9 \%$ & $48 \%$ & $31,6 \%$ \\
2001 & $35,1 \%$ & $46,4 \%$ & $24,1 \%$ \\
\hline
\end{tabular}

FONTE: INE, Recenseamento Geral da População e Habitação, 2001

Em 2001, a proporção dos indivíduos sem qualquer nível de ensino diminuiu para cerca de metade quando comparada com os valores de Recenseamento de 1991, enquanto que a proporção de indivíduos residentes no concelho com nível de instrução do $3^{\circ}$ ciclo do ensino básico e ensino secundário quadruplicou, entre os dois últimos Recenseamentos (GONÇALVES, 2003).

Figura 4. População residente, segundo a condição perante a actividade económica e género, 1991 e 2001

\section{Empregados e Desempregados}

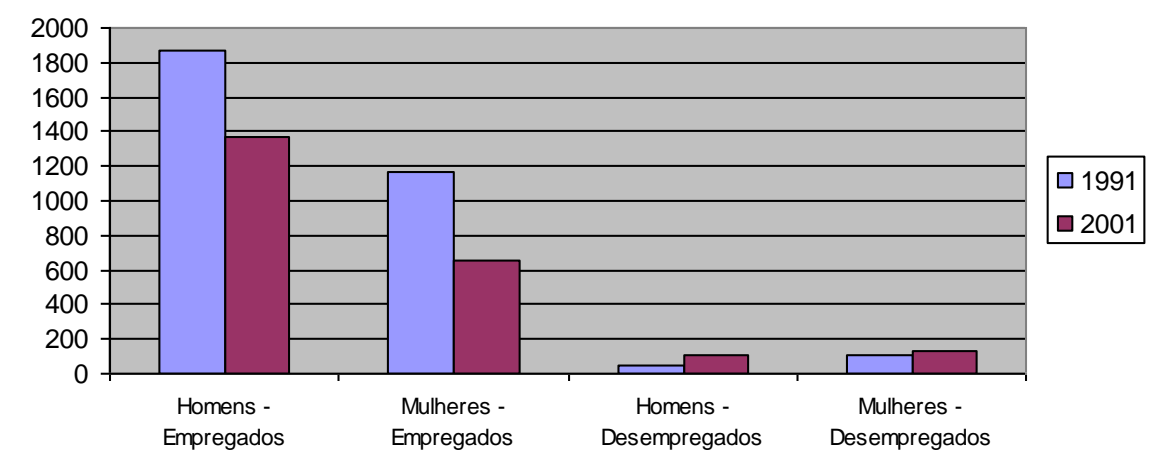

FONTE: INE, Recenseamento Geral da população, 1991 e 2001 
Analisando a composição da população activa segundo a sua situação perante o trabalho, teremos que distinguir a situação de empregado a de desempregado. Os gráficos que se seguem dão-nos informação sobre a composição da população activa em 1991 e 2001, por género (FIGURA 4).

O período em causa denota, para ambos os géneros, uma redução do emprego e um aumento significativo do desemprego. A taxa de desemprego passou de 3,9\% em 1991 para 10,3\% em 2001, afectando essencialmente o grupo das mulheres (FIGURA 5).

Figura 5. Taxa de desemprego

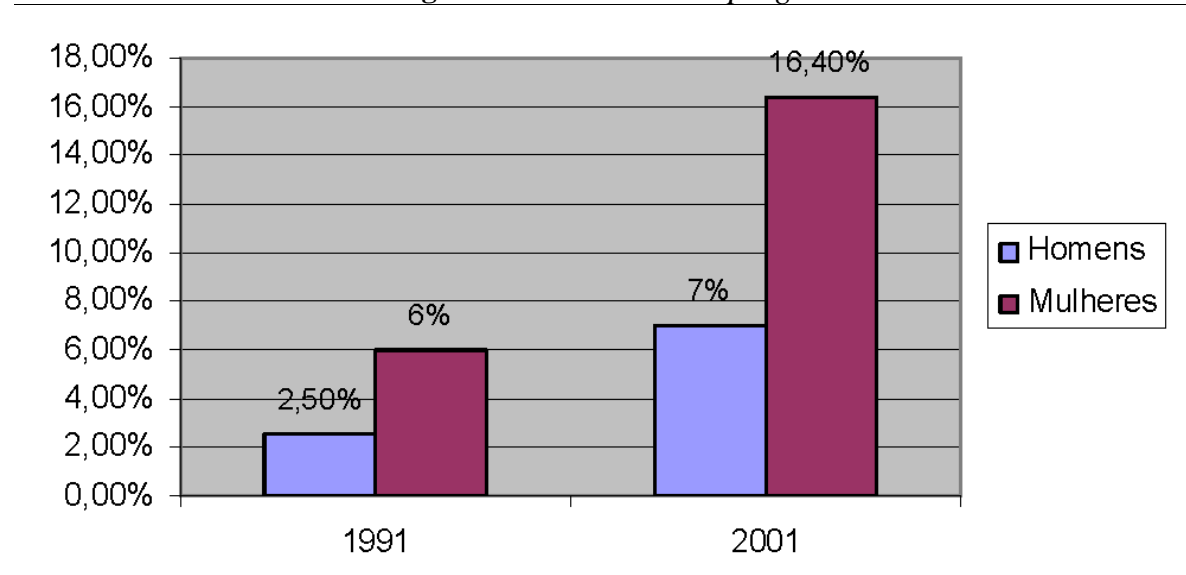

FONTE: INE, Recenseamento Geral da população, 1991 e 2001

Esta evolução parece encontrar resposta, no modelo de especialização seguido na região em termos de indústria e do nível de qualificações. Por outro lado, esta fase de redução do emprego e de aumento significativo de desemprego, essencialmente de desemprego feminino poderá ser um indício de um maior efeito trabalhador desencorajado na região.

A evolução da população activa, entre 1991 e 2001, acentuou a importância dos trabalhadores por conta doutrem e dos patrões e diminuiu o número dos trabalhadores por conta própria, o que se deve à proliferação de unidades económicas no concelho, assim como à transferência da população activa do sector primário para o sector secundário e terciário.

O sector agro-pecuário assumiu, ao longo dos tempos, papel preponderante na ocupação da mão-de-obra da comunidade em estudo. Segundo os dados do Censo de 1991 (INE, 1991), o sector primário ocupava, ainda, 58,7\% da população activa empregada. 
No entanto, este sector encontra-se em franco declínio, uma vez que assenta numa estrutura fundiária muito compartimentada e que os mecanismos de financiamento comunitários têm privilegiado as explorações de grande dimensão, em detrimento da pequena agricultura familiar

O fenómeno agrícola da região é bastante uniforme e monótono. A mãode-obra familiar carece de apoio à inovação ao nível de culturas e processos produtivos cuja ausência se reflecte no baixo rendimento do agregado familiar. Assim, a maioria das famílias em estudo não dependem da agricultura embora esta contribua para os orçamentos de algumas delas. Apesar de a terra continuar a desempenhar um lugar de destaque no sistema de valores dos Barrosões, a economia da região assenta sobretudo no sector secundário e terciário, liderando, em 2001, o grupo das actividades do sector terciário como principal empregador (FIGURA 6).

Figura 6. População residente empregada, por sector de actividade económica no concelho, em 2001

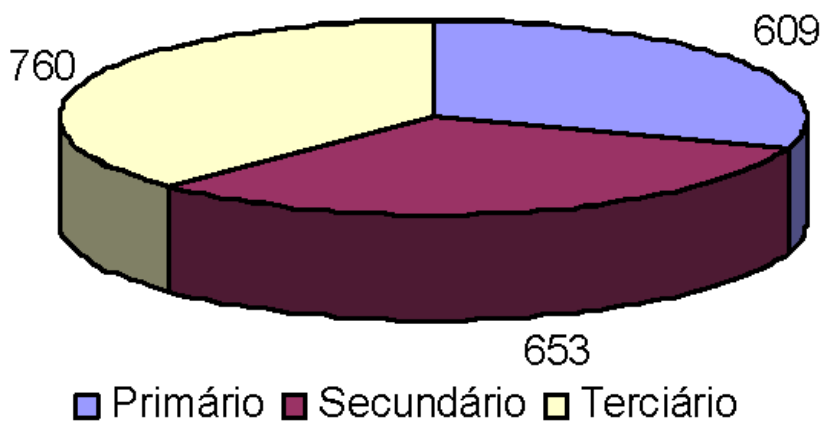

FONTE: INE, Recenseamento Geral da população, 2001

A descida dos activos no sector primário relaciona-se com os movimentos migratórios e com o crescimento do sector dos serviços, sobretudo na sede concelho.

Os subsectores agrário e florestal desempenham um importante papel na economia local. Há, no entanto, graves problemas estruturais que dificultam $\mathrm{o}$ incremento da produtividade. $\mathrm{O}$ reduzido tamanho das explorações, a persistência de técnicas obsoletas com elevados custos, um escasso investimento na melhoria técnica dos processos de cultivo, a falta de formação profissional dos agricultores, e sérios problemas de mercado, sublinham apenas alguns dos mais evidentes. 
Trata-se de um espaço de grande tradição emigratória, onde deparamos já com algum regresso de emigrantes, regresso esse, no entanto, reflectido, na sua maior parte, em pessoas de idade mais avançada.

\section{REGRESSO E DESENVOLVIMENTO}

\section{II.1. Caracterização da amostra}

Verificamos que dos inquiridos regressados ao território de origem, 52,4\% tem mais de 60 anos de idade (QUADRO 3).

Quadro 3: Idade actual

\begin{tabular}{lrr}
\hline \multicolumn{1}{r}{ Idade actual } & $n^{\circ}$ & $\%$ \\
\hline Até aos 30 anos & 7 & 2,4 \\
Dos 30 aos 39 anos & 19 & 6,5 \\
Dos 40 aos 49 anos & 33 & 11,3 \\
Dos 50 aos 59 anos & 80 & 27,4 \\
Mais de 60 anos & 153 & 52,4 \\
\hline \multicolumn{1}{c}{ Total } & 292 & 100,0 \\
\hline
\end{tabular}

Do total de 292 inquiridos, 128 (ou seja, 43,8\% da amostra) concluíram a escola primária. No entanto, 21,2\% (62 indivíduos) não sabe ler nem escrever e 23,3\% (68 indivíduos) sabe ler e escrever, mas não têm grau escolar. É residual, apenas 4 inquiridos, o número de indivíduos emigrantes com estudos superiores (QUADRO 4).

Quadro 4: Nivel de escolaridade

\begin{tabular}{lrr}
\hline & $n^{\circ}$ & $\%$ \\
\hline Não sabe ler nem escrever & 62 & 21,2 \\
Sabe ler e escrever sem grau escolar & 68 & 23,3 \\
Concluiu a escola primária & 128 & 43,8 \\
Concluiu a escola preparatória & 15 & 5,1 \\
Frequentou a escola secundária & 15 & 5,1 \\
Frequentou a universidade & 4 & 1,4 \\
\hline \multicolumn{1}{c}{ Total } & 292 & 100,0 \\
\hline
\end{tabular}

Este facto não causa admiração, já que a lei portuguesa só a partir de 1956 tornou obrigatória a escolarização até ao $4^{\mathrm{a}}$ ano para os homens e, em 1960, para as mulheres. Dado que a maior parte dos inquiridos emigraram na década de 60 e 70, ainda não tinham sido abrangidos por aquela lei. Os níveis de escolaridade são mais elevados nas camadas mais jovens de emigrantes regressados, devido à cada vez maior aposta na instrução, através da escolaridade mínima obrigatória, associada também a uma cada vez mais tardia inserção no mercado de trabalho. 
O nível de escolaridade entre os géneros é algo díspar, nos primeiros níveis de ensino, sobretudo no caso dos indivíduos que sabem ler e escrever sem grau escolar, sendo $64,5 \%$ do sexo masculino e $35,3 \%$ do sexo feminino. A tendência para a homogeneidade acontece nos níveis de escolaridade mais avançados. Dois indivíduos ex-emigrantes de ambos os géneros frequentaram a universidade (QUADRO 5).

Quadro 5: Escolaridade, segundo o género

\begin{tabular}{lrrrr}
\hline & Masculino & \multicolumn{2}{c}{ Feminino } \\
\cline { 2 - 5 } & $n^{o}$ & $\%$ & $n^{o}$ & $\%$ \\
\hline Não sabe ler nem escrever & 35 & 56,5 & 27 & 43,5 \\
Sabe ler e escrever sem grau escolar & 44 & 64,7 & 24 & 35,3 \\
Concluiu a escola primária & 70 & 54,7 & 58 & 45,3 \\
Concluiu a escola preparatória & 8 & 53,3 & 7 & 46,7 \\
Frequentou a escola secundária & 8 & 53,3 & 7 & 46,7 \\
Frequentou a universidade & 2 & 50,0 & 2 & 50,0 \\
\hline \multicolumn{1}{c}{ Total } & 167 & 57,2 & 125 & 42,8 \\
\hline
\end{tabular}

\section{II.2. Tempo de estadia no país de imigração e ano de regresso}

Dos inquiridos, 40,1\%, (111) esteve ausente do país de origem até 5 anos. Estiveram ausentes até 10 anos (10,8\%) 30 indivíduos. Até 20 anos, encontramos 57 inquiridos $(20,6 \%), 45$ inquiridos $(16,2 \%)$ estiveram emigrados até 30 anos. Apenas 34 inquiridos (12,3\%) estiveram mais de 30 anos emigrados. Em média, os inquiridos estiveram emigrados cerca de 17 anos no país de acolhimento (FIGURA 7).

Figura 7. Tempo de estadia do emigrante regressado no país de imigração

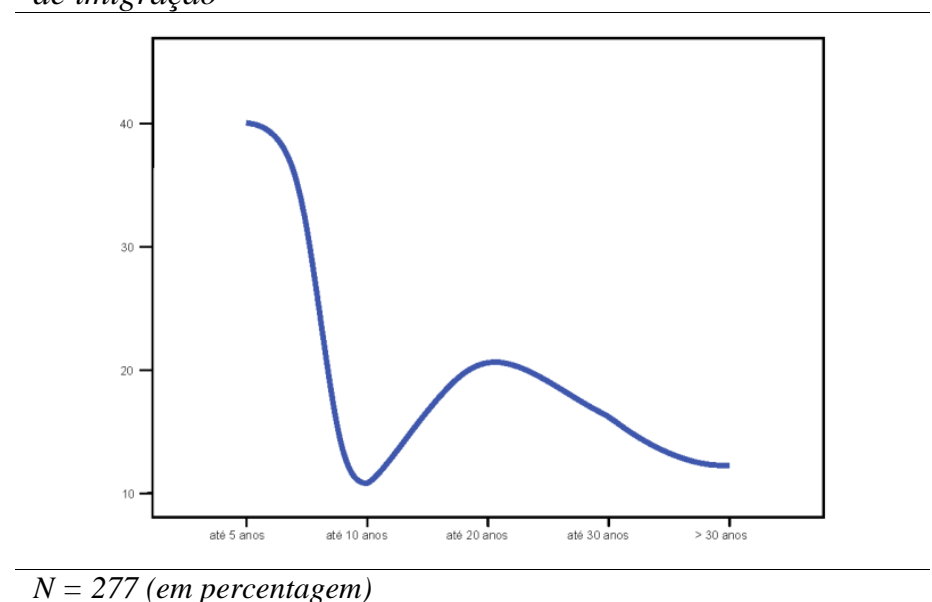

$N=277$ (em percentagem) 
Existe consenso entre os investigadores no campo da emigração, segundo o qual emigrantes procuram regressar somente depois de terem conseguido atingir os objectivos económicos propostos à partida.

Analisando o tempo de estadia no país de imigração, por género, segundo a idade de regresso, conclui-se naturalmente que, quanto maior é o tempo de emigração, maior é a idade no regresso. Observamos uma ligeira predominância de indivíduos do género masculino a emigrar durante períodos mais longos, o que indicia tempos de estadias superiores. Não obstante, o tempo de estadia até 5 anos mantém-se como predominante em ambos os géneros.

Em relação ao tempo de estadia segundo o primeiro país de imigração, verificamos que a França abarca, de forma decisiva, os maiores períodos de permanência no país de acolhimento. De salientar os 12 inquiridos na faixa dos 5 anos de emigração no Brasil. Os restantes países apresentam valores residuais, ofuscados claramente pelo peso esmagador do fluxo emigratório para a França, independentemente do tempo de estadia.

Constatamos que os inquiridos regressaram essencialmente entre 1975 e 1996, correspondendo 38,9\% à década de 1975-1985 e 30,7\% ao período entre 1986 e 1996.

Tal impulso de regresso encontra a sua explicação na instauração de medidas e políticas de imigração impostas pelos governos dos principais países de acolhimento e já por nós referidas, tendo, inclusive, coincidido com a mudança do regime político português. O regresso dos emigrantes continua embora em menor proporção, constituindo $23,0 \%$ da amostra em estudo entre 1997-2003. Quanto ao ano de regresso, também não foram encontradas diferenças significativas de género.

\section{II.3. Motivos de regresso e quadro familiar do ex-emigrante}

Em diferentes partes do Mundo, vários investigadores têm estudado a emigração de regresso (BRETTELL 1979; GMELCH 1980, 1983, 1987, 1992; GUARNIZO 1997; KENNEY 1986; LOCKWOOD 1990; RHOADES 1978a; STACK 1996; TAYLOR 1976; THOMAS-HOPE 1985). GMELCH (1980) sustenta que a maior parte dos estudos indicam que os fortes laços familiares, em vez dos factores económicos, são o maior incentivo para o regresso.

No presente estudo, os motivos familiares, nomeadamente a garantia da unidade familiar, foi a principal razão do regresso (23,3\%, 63 inquiridos). As saudades e o amor à terra natal surgem em segundo lugar, com 11,9\%, (32 inquiridos), o que é revelador da ânsia de regresso às raízes. 
Quase sem relevância, surgem as razões políticas (1,9\%, 5 inquiridos) e a falta de condições de acolhimento no país de imigração $(0,4 \%, 1$ inquirido) (GONÇALVES, 2009).

STACK (1996, p.15), estudando os africanos na América do Norte, chega às mesmas conclusões quanto aos motivos de regresso dos emigrantes, “(...) o resolver regressar a casa não é primeiramente uma decisão económica mas uma mistura poderosa de motivos. As pessoas sentem uma obrigação de ajudar os seus parentes, ..."

No entanto, outras causas explicativas do regresso dos emigrantes ao seu país de origem têm sido apontadas por vários especialistas no campo das migrações. Por exemplo, a migração de regresso pode ser relacionada com experiências de racismo e de discriminação (TAYLOR, 1976) ou até com incentivos financeiros oferecidos pelo país acolhedor, encorajando os imigrantes ao regresso, como aconteceu, após 1973, na Europa Ocidental. O regresso pode ser também parte da estratégia de migração inicial, frequentemente adiada.

Dos inquiridos, 43,8\% indicaram a permanência dos seus filhos no país de imigração É compreensível que os filhos mais jovens tenham acompanhado os seus progenitores no seu regresso, mas os filhos já em idade activa encontraram razões para se manterem no país que os acolheu. As melhores condições de vida $(64,1 \%, 91$ inquiridos) e salários mais elevados $(29,6 \%, 42$ inquiridos), são os principais motivos apresentados pelos ex-emigrantes para justificar a permanência dos seus descendentes no país de imigração. Afirmam $4,2 \%$ (6 inquiridos) que os filhos permaneceram no país de imigração devido aos estudos e 2,1\% (3 inquiridos) indicam outras razões.

\section{II.4. Mobilidade sócio-ocupacional}

Após o regresso, muitos dos inquiridos vivem na situação de reformado (123 indivíduos); outros tornam-se patrões, sendo este último estatuto, relativamente à situação na profissão, a mudança mais significativa encontrada, com as consequentes implicações económicas e sociais (QUADRO 6).

A principal ocupação profissional do ex-emigrante, após o regresso, é claramente a agricultura, seguindo-se os serviços domésticos, o sector da construção civil e o comércio, tornando-se evidente alguma mobilidade intersectorial do ex-emigrante, relativamente às ocupações exercidas antes de emigrarem (QUADRO 7).

As mudanças ocupacionais do emigrante regressado ao Concelho de Boticas, ao longo da sua trajectória migratória (emigração - regresso), estiveram 
sujeitas a níveis crescentes de mobilidade, para ocupações gradativas na escala sócio-ocupacional, mas também em direcção à inactividade e desocupação. Recordamos que, antes da emigração, a maior parte dos inquiridos eram trabalhadores familiares, não existindo ninguém a viver de rendimentos. Após o regresso, muitos vivem na situação de reformado, enquanto que outros vivem dos rendimentos auferidos no país de acolhimento. A maioria dos emigrantes regressados considera, após a chegada, "razoáveis" o seu poder de compra e nível de vida, seguindo-se (com valores ainda bastante relevantes) os inquiridos que afirmam ter um poder de compra e nível de vida entre bom e excelente. Este item demonstra claramente que o objectivo principal da emigração (aquisição de melhores condições económicas) foi cumprido.

Quadro 6: Situação na profissão após o regresso

\begin{tabular}{|c|c|c|}
\hline & $n^{o}$ & $\%$ \\
\hline A trabalhar como Patrão & 51 & 18,0 \\
\hline A trabalhar por conta de outrem & 40 & 14,1 \\
\hline Desempregado & 8 & 2,8 \\
\hline Doméstica & 31 & 10,9 \\
\hline Reformado & 123 & 43,3 \\
\hline Vive dos rendimentos & 28 & 9,9 \\
\hline Outra situação & 3 & 1,1 \\
\hline Total & 284 & 100,0 \\
\hline
\end{tabular}

Quadro 7: Ocupação profissional antes da emigração e após o regresso

\begin{tabular}{|c|c|c|}
\hline Antes da emigração & $n$ & $\%$ \\
\hline Agricultura & 206 & 71,8 \\
\hline Construção Civil & 20 & 7,0 \\
\hline Serviços Domésticos & 33 & 11,5 \\
\hline Comércio & 14 & 4,9 \\
\hline Carpintaria & 1 & 0,3 \\
\hline Outros & 13 & 4,5 \\
\hline Total & 287 & 100,0 \\
\hline Antes da emigração & $n$ & $\%$ \\
\hline Agricultura & 130 & 53,7 \\
\hline Jardinagem & 4 & 1,7 \\
\hline Construção Civil & 21 & 8,7 \\
\hline Transportes e Comunicações & 2 & 0,8 \\
\hline Têxteis, Vestuário e Calçado & 2 & 0,8 \\
\hline Indústria Transportadora & 1 & 0,4 \\
\hline Comércio & 18 & 7,4 \\
\hline Serviços Domésticos & 44 & 18,2 \\
\hline Restaurante & 4 & 1,7 \\
\hline Outros & 16 & 6,6 \\
\hline Total & 242 & 100,0 \\
\hline
\end{tabular}




\section{II.5. Impacto local do ex-emigrante}

Observamos algum envolvimento/empenho dos ex-emigrantes na vida política e associativa local. Independentemente dos motivos que tenham levado os indivíduos à emigração e ao regresso ao local de origem, a integração nas estruturas sociais preexistentes do local de chegada pressupõe um ajustamento às regras e valores vigentes. Perante a dificuldade individual de integração, os indivíduos congregam esforços e iniciativas com a finalidade de alcance de objectivos comuns, agrupando-se em estruturas formais de âmbito mais alargado. $\mathrm{O}$ associativismo de migrantes constitui uma forma institucionalizada de reforço do grupo perante ameaças exteriores.

As principais inovações introduzidas, a nível local, pelo emigrante regressado prendem-se com a habitação, hábitos alimentares, formas de vestir, relações pessoais e tempos livres e, quanto à agricultura, a introdução de equipamentos novos e novas formas de produção. No regresso, as principais carências locais com que se deparam dizem respeito sobretudo a: assistência médica, subsídios, dificuldades para a conclusão dos estudos dos filhos.

O dinamismo empresarial de alguns emigrantes regressados, ao território em estudo, tem feito renascer alguns mercados locais, gerando inclusive o aparecimento de novas actividades. Apresentamos seguidamente os resultados de seis inquéritos por entrevista feitos por nós a emigrantes regressados. Segundo RUQUOY (em ALBARELLO et al. 1997), "as entrevistas permitem uma compreensão rara e matizada das situações que se relacionam com a forma de ver o mundo, as intenções e crenças dos indivíduos..." (ALBARELLO et al, 1997, p. 84). Esta análise integra quatro eixos de caracterização: (1) Identificação do empresário - Características demográficas e socioculturais e história de vida (mobilidade geográfica, percurso académico e profissional, motivações pessoais e constituição familiar); (2) Identificação, caracterização e evolução da empresa; (3) Apoio institucional e perspectivas de desenvolvimento concelhio; (4) Avaliação global da empresa (grau de satisfação, factores de in(sucesso) e impacto da empresa a nível local).

Sintetizamos o seguinte, sobre os emigrantes regressados inquiridos:

$\checkmark$ A idade média é de 47,6 anos;

$\checkmark$ Os empresários são autóctones ou ligados ao concelho em estudo por laços familiares;

$\checkmark$ Somente um dos entrevistados apresenta dupla nacionalidade;

$\checkmark$ As habilitações literárias variam desde $04^{\circ}$ ano até ao $12^{\circ}$ ano;

$\checkmark$ Apresentam formação diversificada adquirida no país de imigração; 
Constata-se que a maior parte dos empresários em estudo estão ligados a alguns tipos de associações;

$\checkmark$ Registam mobilidade profissional ascendente;

$\checkmark$ Foram imigrantes predominantemente em França;

$\checkmark$ Identificam-se como cidadãos europeus, com excepção de um dos entrevistados;

$\checkmark$ Apresentam elevada mobilidade geográfica anterior ao regresso

- ramo de actividade das empresas analisadas é diversificado;

$\checkmark$ As empresas localizam-se na sede de concelho, exceptuando o Hotel com localização na freguesia de Beça;

$\checkmark$ As empresas são de pequena dimensão e de baixo volume de vendas, apresentando na generalidade evolução positiva;

$\checkmark$ Todas as empresas apresentam forma jurídica em nome individual e estrutura familiar em termos de capital social e quanto à composição dos recursos humanos;

- capital social provém essencialmente da poupança, embora também sejam referidos o crédito bancário e fundos comunitários, respectivamente por dois e um inquiridos;

$\checkmark$ As empresas apresentam boas perspectivas de crescimento e projectos futuros;

$\checkmark$ As empresas são direccionadas para o mercado local/regional.

$\checkmark$ A reacção da comunidade à implementação das empresas em estudo segue uma perspectiva determinista, face ao contexto territorial;

$\checkmark$ A promoção da imagem das empresas é feita essencialmente pela rádio e pela Internet.

$\checkmark$ Os empresários encontram-se geralmente satisfeitos com as suas empresas;

- impacto das empresas a nível concelhio é positivo e reflecte-se na criação de: emprego, riqueza, sinergias e investimentos.

$\checkmark$ As empresas em análise revelam escasso apoio institucional. Os empresários geralmente desconhecem as vantagens/impactes dos fundos estruturais; consideram inclusive a desadequação das exigências dos programas às realidades locais;

- impacto das empresas a nível local é geralmente positivo, reflectindo criação de emprego, de riqueza e sinergias locais;

$\checkmark$ Os entraves ao desenvolvimento resumem-se em falta de vias de comunicação, despovoamento, débil marketing territorial, falta de infraestruturas, escassa mão-de-obra especializada, escasso emprego, forte envelhecimento populacional e salários baixos, burocracia, baixo poder de compra; 
As oportunidades de desenvolvimento para as empresas baseiam-se essencialmente em: incentivos fiscais, proximidade fronteiriça, ambiente natural, mão-de-obra barata;

$\checkmark$ As estratégias de dinamização da economia local passam pela implementação de pequenas e médias indústrias ligadas à horticultura, à madeira, à produção de carnes regionais, criação de uma cooperativa agrícola para escoamento dos produtos locais, pelo fomento do turismo e revitalização da floresta e pela captação da energia eólica.

\section{STATUS QUO DA INTERVENÇÃO TERRITORIAL EM BOTI- CAS}

Tendo em atenção os três pilares básicos do desenvolvimento: ambiente, economia e sociedade, encontramos no espaço territorial apresentado, estrangulamentos em todos eles. Julgamos importante identificar as virtudes e carências deste território para que sejam delineadas estratégicas fundamentais a desenvolver já que, somente superando os pontos fracos e reforçando os pontos fortes, com o consequente aproveitamento e valorização das potencialidades existentes, poderemos direccionar os espaços geográficos para o desenvolvimento sustentável.

\section{III.1. Pontos fortes}

Como pontos fortes podemos considerar:

$\checkmark$ Grande diversidade de fauna e flora;

$\checkmark$ Importância das explorações com DOP (Carne Barrosã, mel do Barroso) e com IGP (Cabrito de Barroso, Presunto do Barroso);

$\checkmark$ Património molinológico;

$\checkmark$ Zona de paisagem protegida;

$\checkmark$ Crescente interesse por desportos radicais;

$\checkmark$ Procura crescente de actividades ligadas à natureza;

$\checkmark$ Boa utilização dos fitofármacos e químicos na agricultura;

$\checkmark$ Múltiplos projectos e iniciativas de Desenvolvimento Local apresentam características diferenciadas, sendo uma das suas principais riquezas;

$\checkmark$ Importância do surgimento de novas formas de turismo, mais sensíveis às questões ambientais, à cultura, aos circuitos pedestres, etc.

$\checkmark$ Culturas rurais em que sobressaem as feiras e mercados, as festas e romarias tradicionais;

$\checkmark$ Existência de nascente minero-medicinal em Carvalhelhos;

$\checkmark$ Disponibilidade de artesanato vivo, em especial - burel, linho, bordados, socos de pau, miniaturas, em madeira, de bois, grades, etc. 
$\checkmark$ Confraria Gastronómica da Carne Barrosã;

$\checkmark$ Cooperativa local de apoio aos produtos agrícolas do Concelho;

$\checkmark$ Boas condições cinegéticas (coelho, perdiz, raposa) e piscícolas (truta e outros);

$\checkmark$ Existência de condições para o desenvolvimento de uma boa e típica gastronomia, baseada no produto da caça e da pesca, não esquecendo a tenra e suculenta Carne Barrosã;

$\checkmark$ Importantes apoios comunitários dos programas AGRO, AGRIS e Leader+, no apoio à modernização da actividade agroflorestal, da preservação ambiental e do desenvolvimento rural sustentável.

\section{III.2. Pontos Fracos}

Como pontos fraco, podemos referir:

$\checkmark$ Diminuição da população - sobretudo dos mais jovens;

$\checkmark$ Idade avançada dos agricultores;

$\checkmark$ Abandono crescente e grande desinteresse pela actividade agrícola;

$\checkmark$ Insuficiente formação profissional;

$\checkmark$ Inexistência de saneamento básico e de tratamento de afluentes;

$\checkmark$ Carência de equipamentos de apoio ao turismo;

$\checkmark$ Descaracterização urbanística;

$\checkmark$ Pequena dimensão e fragmentação da exploração agrícola;

$\checkmark$ Analfabetismo e baixa qualificação;

$\checkmark$ Carência de equipamentos de apoio às crianças em idade escolar e aos idosos, ao nível das aldeias;

$\checkmark$ Insuficiente aproveitamento dos produtos endógenos com potencialidades;

$\checkmark$ Excessivo protagonismo pessoal na condução e gestão de alguns projectos;

$\checkmark$ Falta de recursos (financeiros, humanos, materiais, etc.)

$\checkmark$ Excessiva dependência do exterior (em ideias, recursos humanos, mercados, etc.);

$\checkmark$ Dificuldade em levar à prática uma perspectiva interdisciplinar, por falta de técnicos em algumas áreas;

$\checkmark$ Pouca ligação com grupos e centros de investigação;

$\checkmark$ Dificuldade de escoamento de produtos e de ligação ao mercado;

$\checkmark$ Inadequação de alguns programas (por exemplo, de formação profissional) às características das populações e às situações a que os projectos procuram responder;

$\checkmark$ Défice de capacidade de iniciativa de algumas zonas de intervenção;

$\checkmark$ Inexistência de uma tradição de acolhimento turístico e limitada capacidade de alojamento; 
Escasso apoio dado aos turistas no posto de turismo, que se encontra, a maior parte das vezes, fechado;

$\checkmark$ Ausência de postos de apoio a percursos equestres;

$\checkmark$ Panorama de escolaridade pouco satisfatório, com elevadas taxas de analfabetismo, de insucesso e de abandono;

$\checkmark$ Serviço de transportes públicos insuficientes às necessidades da população;

$\checkmark$ Debilidade e relativa pouca extensão da rede viária nacional secundária, que serve de base às deslocações predominantes de tipo local e à circulação de Transportes Rodoviários de Passageiros;

$\checkmark$ Tecido económico incapaz de garantir a auto-sustentação do desenvolvimento e falta de iniciativa empresarial;

$\checkmark$ Falta de oportunidades de emprego e consequente rarefacção do pessoal qualificado;

$\checkmark$ Degradação das matas e desinteresse, sob o ponto de vista económico, dos agricultores pela floresta, favorecendo incêndios, desvalorizando o património florestal e criando externalidades negativas na paisagem;

$\checkmark$ Índices de poder de compra e do PIB, per capita, claramente inferiores à média nacional;

$\checkmark$ Reduzida dinâmica em matéria de diversificação sectorial, problemas tirando o reforço da competitividade e a modernização da base produtiva do concelho;

$\checkmark$ Inexistência de uma programação cultural e desportiva regular que promova práticas e hábitos diversificados e que ultrapasse as dinâmicas mais tradicionais;

$\checkmark$ As deficientes condições de acessibilidade interna e externa do concelho, de segurança rodoviária e de sinalização afectam, de forma sensível, as condições de mobilidade e de coesão.

Figura 8. Tempo de estadia do emigrante regressado no país de imigração

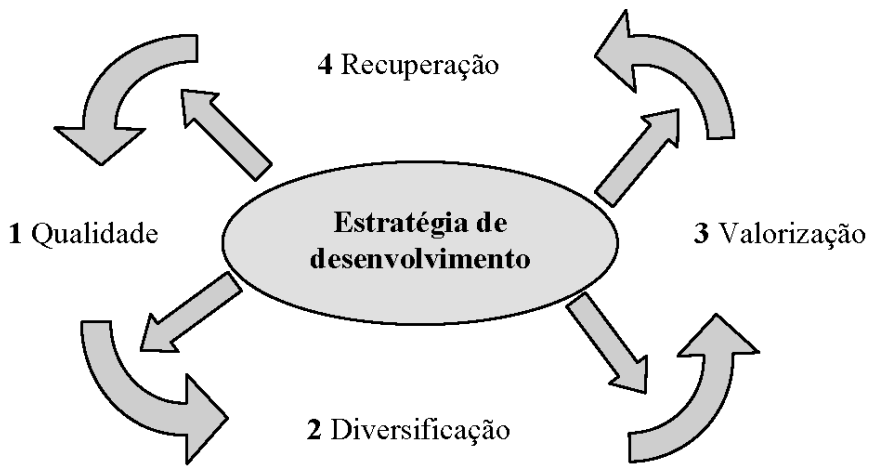


Valorizando os pontos fortes e tentando diminuir o impacto dos pontos fracos, propomos, para o território de Boticas, uma estratégia de desenvolvimento assente em 4 parâmetros fundamentais (FIGURA 8).
$\checkmark 1$ - Qualidade ambiental e paisagística
$\checkmark 2$ - Diversificação das actividades
$\checkmark 3$ - Valorização dos recursos naturais, culturais e humanos
$\checkmark 4$ - Recuperação do património

\section{Consideramos prioritários 7 eixos de intervenção, a referir:}

Quadro 8: Prioridades estratégicas. Eixos de Intervenção

\begin{tabular}{|c|c|}
\hline $\begin{array}{c}\text { Actividades eco- } \\
\text { nómicas }\end{array}$ & $\begin{array}{l}\checkmark \text { Introdução de técnicas apropriadas de serração, secagem, calibragem } \\
\text { e armazenamento da madeira; controlo da qualidade, eficiência ener- } \\
\text { gética e utilização dos resíduos florestais. } \\
\checkmark \text { Formação profissional. } \\
\checkmark \text { Apoio ao ensino do artesanato de forma a garantir a continuidade dos } \\
\text { ofícios. } \\
\checkmark \text { Promoção da realização de feiras e mostras de artesanato. } \\
\checkmark \text { Aproveitamento de energia eólica. } \\
\checkmark \text { Apoio às pequenas indústrias locais. } \\
\checkmark \text { Reforço do espírito empresarial e associativo. } \\
\checkmark \text { Organização de circuitos de comercialização. } \\
\checkmark \text { Apoio à exploração de ervas aromáticas, cogumelos silvestres, quei- } \\
\text { jos do Barroso, silvopastorícia, fumeiro tradicional, carne Barrosã e } \\
\text { agricultura biológica. } \\
\checkmark \text { Apoio à criação e dinamização de associações de produtos florestais. } \\
\checkmark \text {.Criação de pequenas lojas de venda de mel do Barroso, presunto etc. }\end{array}$ \\
\hline $\begin{array}{c}\text { Infraestruturas e } \\
\text { equipamentos }\end{array}$ & $\begin{array}{l}\checkmark \text { Reforço da rede de infraestruturas de protecção social (creches, jar- } \\
\text { dins de infância, lares e centros de dia) e promoção da realização de } \\
\text { acções diversificadas de apoio social. } \\
\checkmark \text { Construção de novas infraestruturas de saúde e higiene e reforço da } \\
\text { prestação de cuidados de saúde. } \\
\checkmark \text { Reforço da capacidade técnica local para funções de planeamento, } \\
\text { programação, acompanhamento e avaliação das acções de desenvol- } \\
\text { vimento. } \\
\checkmark \text { Melhoria das acessibilidades. } \\
\checkmark \text { Reforço das redes de transporte público. } \\
\checkmark \text { Tratamento dos afluentes-águas residuais domésticas. } \\
\checkmark \text { Recolha e tratamento dos resíduos sólidos urbanos. } \\
\checkmark \text { Criação de espaços de apoio escolar. } \\
\checkmark \text { Identificação e/ou sinalização correctas das memórias ligadas ao Pa- } \\
\text { trimónio Cultural e aos valores do património natural. }\end{array}$ \\
\hline Turismo & $\begin{array}{l}\checkmark \text { Incentivo ao turismo jovem: Pousada da Juventude. } \\
\checkmark \text { Fomento do Turismo Rural. } \\
\checkmark \text { Fomento do Turismo de Natureza. } \\
\checkmark \text { Fomento do Agro-Turismo. } \\
\checkmark \text { Recuperação dos moinhos e dos fornos } \\
\checkmark \text { Apoio à restauração e criação de alojamento turísticos. }\end{array}$ \\
\hline
\end{tabular}




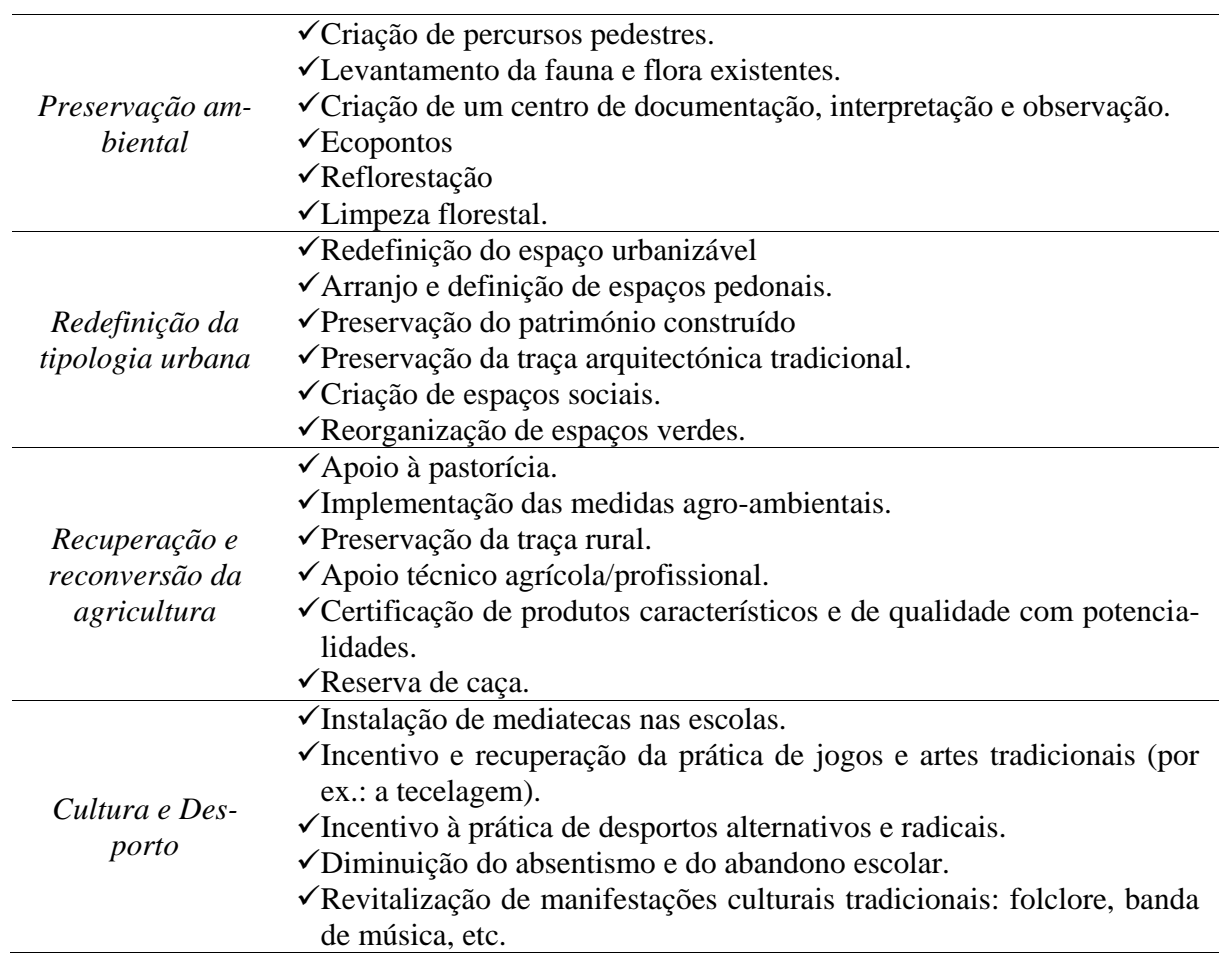

\section{CONCLUSÃO}

O impacto do regresso sobre a dinâmica económica concelhia diminui em razão da idade avançada de uma grande parte dos emigrantes regressados, da baixa escolaridade e, principalmente, da inclusão no sector primário, o que reflecte, na generalidade, o baixo investimento em capital humano no país de acolhimento.

Embora sendo mais agentes de consumo do que de investimento, registase, entretanto, uma introdução clara de novos hábitos, por parte dos emigrantes regressados, proporcionando uma certa urbanidade local. Os exemigrantes de faixas etárias mais jovens revelam espírito empreendedor, tendo, inclusive, feito renascer alguns mercados locais, gerando emprego e o aparecimento de outras actividades.

O Concelho de Boticas é uma zona do interior de Portugal em que predominam actividades com baixo nível de produtividade e de rendimento, com subemprego crónico, mão-de-obra pouco qualificada e população envelhecida. Apresenta elevadas qualidades ambientais e paisagísticas às quais estão associadas inúmeras oportunidades que é urgente desenvolver. 
Torna-se necessário encontrar um equilíbrio entre desenvolvimento, preservação e consequente erradicação da pobreza, no quadro de políticas de desenvolvimento concebidas a dois níveis: políticas de base e políticas territorialmente específicas de avaliação das necessidades de desenvolvimento local, fixando/atraindo população.

As estratégias de dinamização da economia local passarão por:

$\checkmark$ Aumentar a competitividade dos sectores agrícola e florestal;

$\checkmark$ Revitalizar económica e socialmente todo o espaço rural;

$\checkmark$ Reforçar a coesão territorial e social;

$\checkmark$ Promover a eficácia da intervenção dos agentes públicos, privados e associativos na gestão territorial e sectorial;

$\checkmark$ Potenciar o papel dos ex-emigrantes enquanto agentes para o desenvolvimento, promovendo o seu envolvimento nos projectos de execução transnacional, favorecendo um ambiente inovador;

$\checkmark$ Dotar a população das prerrogativas necessárias ao desenvolvimento: informação, acesso ao micro crédito, formação profissional direccionada para oportunidades locais - importantes factores a montante da inovação;

$\checkmark$ Fomentar o espírito empreendedor local, o sentido de risco e a criatividade, enquanto instrumentos de desenvolvimento e consequentes incentivos à fixação da população local e ao regresso dos emigrantes.

\section{BIBLIOGRAFIA}

Albarello, L. et al., (1997): Práticas e Métodos de Investigação em Ciências Sociais, Lisboa, Gradiva.

BragA, D. (1993): Industrialização e Desenvolvimento em Meios Rurais, Lisboa, S.M.

BRETTEL, C. (1979): «Emigrar para voltar: A portuguese Ideology of Return Migration», Anthropology, $\mathrm{n}^{\circ}$ 20, 1-20.

CAstles, S. (2005): Globalização, Transnacionalismo e Novos Fluxos Migratórios dos Trabalhadores Convidados às Migrações Globais, Lisboa, Edições Fim de Século.

GLICK, S. (1977): «Ethnic Groups are Made, Not Born: The Haitian Immigrant and American Politics», in GEORGE H. and PHILIP L. (eds.), Ethnic encounters: Identities and Contexts, Belmont, Wadsworth, 23-35.

Gonçalves O. (2009): Migrações e Desenvolvimento. Os Portugueses no Mundo, Colecção 2. Cepese, Porto, Fronteira do Caos Editores.

GonçALVES, O. (2003): »Emigração, Retorno e Desenvolvimento Sustentável no Barroso» Dissertação de Mestrado em Relações Interculturais, Universidade Aberta. 
GuARnizO, L. (1997): «The Emegence of a Transnacional Social Formation and the Mirage of Return Migration among Dominican Transmigrants», Identities, $\mathrm{n}^{\circ} 4$, 281-322.

KEARNEY, M. (1986): «From the Invisible Hand to Visible Freet: Anthropological Studies of Migration and Development», Annual Review of Anthropology, $\mathrm{n}^{\circ}$ 15, 331-404.

LEVIT, P. (1998): Local-Level Global Religion: The Case of U.S. - Dominican Migration», Journal for the Scientific Study of Religion $n^{\circ} 37,74-89$.

Lockwood, V. (1990): «Development and Return Migration to Rural French Polynésia», International Migration Review, $\mathrm{n}^{\circ}$ 24, 347-71.

MARTins, B. (1992): Concelho de Boticas, a sua História, Ed. Câmara Municipal de Boticas.

PORTES, A. (1999): Migrações Internacionais - Origens, Tipos e Modos de Incorporação, Oeiras, Celta Editora.

RHOADES, R. (1978a): «Intra-European Migration and Rural Development: Lessons from the Spanish Case», Human Organization" n 37, 136-47.

Rato, H. et AL., (2000): Uma Migração de Sucesso: Os Portugueses em Fran ça, Lisboa, CEDEP.

SWINBURN, G., et al., (2004): Local economic development: a primer developing an implementing local economic development strategies and action plans, Londres, The World Bank.

StaCK, C. (1996): Call to Home: African Americans Reclain the Rural South, Nueva York, Basic Books.

TABordA, V. (1987): Alto Trás-os-Montes - Estudo Geográfico, Lisboa, Livros Horizonte.

TAYLOR, E. (1976): «The Social Adjustment of Returned Migrants to Jamaica», in Frances HENRY, ed., Ethnicity in the Americas, The Haune, Mouton, 213-30.

THOMAS-HOPE, E. (1985): «Return Migration and its Implications for Caribbean Development: The Unexplored Connection», in PASTOR, R. (ed.) - Migration and Development in the Caribbean: The Unexplored Connection, Boulder, Westview Press.

WeINER, M. (1995): The Global Migration Crisis: Challenge to Status and to Human Rights, Nuvea York, Harper Collins Publishers.

WERBNER, P. (1988): «Taking and giving: working women and female bonds in a Pakistani immigrant Neighbourhood», en WeSTwOOD, S., BlACHU, P. (eds.), Enterprising Women, Ethnicity, Economy and Gender Relations, Londres, Routledge, 177-202.

WERBNER, P. (1996): «Stamping the Earth with the Name of Allah: Zikr and the Sacralizing of Space among British Muslims», en Metcalf, B. (ed.), Making Muslim Space in North America and Europe, Berkeley, University of California Press, 167-85.

WILSON, T. (1994): «What Determines Where Transnational Labor Migrants Go? Modification in Migration Theories», Human Organization 53(3), 269-78. 